für Schnee- und Lawinenforschung at I : 10 ooo included in 26 advisory reports on 56 I individual avalanche paths, and which can act as pilot studies to assist cantons in preparing their own maps.

This paper is being published in full in German in Interpraevent 1980 , Bd. 3, as part of the proceedings of the symposium held at Bad Ischl, Austria, 8-12 September 1980.

\title{
CONSTANT STRAIN-RATE TENSILE TESTING OF NATURAL SNOW
}

\author{
By H. Singh and F. W. Smith \\ (Department of Mechanical Engineering, Colorado State University, Fort Collins, \\ Colorado $805^{23}$, U.S.A.)
}

Abstract. In conducting tension and compression tests on snow samples, strains and strain-rates are usually determined from the displacements of the ends of the samples. In this work, a strain-gage which mounts directly onto the snow sample during testing, was developed and was found to give accurate and direct measurements of strain and strain-rates.

A commercially available $0-28 \mathrm{pF}$ variable capacitor was modified to perform the required strain measurements. It is a polished metallic plunger sliding inside a metal-coated glass tube. The plunger and tube were each soldered to the end of a spring-steel wire arm. To the other end of these arms were soldered ro mm square pads made of thin brass shim stock. The whole device weighs $2.5 \mathrm{~g}$ and the low coefficient of friction in the capacitor resulted in a very low actuation force. To mount the strain gage, the pads are wetted and frozen onto the snow sample.

A high degree of sensitivity was achieved through the use of "phase-lock-loop" electronic circuitry. The capacitance change caused by the strain in the sample, changes the frequency of output signal from an oscillator and thus causes the change in output from the system. In the locked state, to which the system is constantly driven by a feed-back loop, the system output is almost ripple free.

The strain gages were calibrated in the field in order to take into account the effects of very low field temperatures. The calibration curves were almost linear over the travel of I $5 \mathrm{~mm}$, the maximum limit. The sensitivity of the system is $4 \mathrm{mV}$ per strain unit, but this could be increased by an order of magnitude by minor adjustments in the circuit.

Constant strain-rate tensile tests were performed on natural snow at Berthoud Pass, Colorado, U.S.A., in the density range of $140-290 \mathrm{~kg} \mathrm{~m}^{-3}$. Four strain gages were mounted onto the samples to sense any non-uniform deformation which otherwise would have gone unnoticed or caused scatter in the data. The average indication of these gages was used to construct stress-strain curves for various types of snow at different strain-rates. The effect of strain-rate on the behavior of snow was studied.

"Ratcheting" in the stress-strain curve in the region where the snow becomes plastic was observed first by Kinosita in his compression tests. A similar phenomenon was observed in these tension tests. It was found that directly measured strain is quite different from that which would be calculated from sample end movement. Strain softening was not observed in these tests up to total strains of $8 \%$. The strain-rate effects found were comparable to the results of other investigators. 